\title{
Micropropagation of Tilia amurensis via Repetitive Secondary Somatic Embryogenesis
}

\author{
Tae Dong Kim ${ }^{1,2^{*}}$, Yong Eui Choi ${ }^{2}$, Byoung Sil Lee ${ }^{1}$, Young Joung Kim', Tae Su Kim \\ and In Sik Kim ${ }^{1}$
}

${ }^{1}$ Forest Seed Research Center, Korea Forest Research Institute, Chungju 380-940, Korea; ${ }^{2}$ Division of Forest Resources, College of Forest an Environmental Sciences, Kangwon National University, Chunchon 200-701, Korea

\begin{abstract}
A optimal procedure for plant production via repetitive secondary somatic embryogenesis in Tilia amurensis is described. Somatic embryos were induced directly from the culture of zygotic embryos on medium with $1.0 \mathrm{mg} / \mathrm{l} 2,4-\mathrm{D}$. Repetitive secondary somatic embryos formed on the surface of the cotyledons and hypocotyls except for the radicles when explants of somatic embryos were cultured on medium with $1.0 \mathrm{mg} / \mathrm{l} 2,4-\mathrm{D}$. The highest frequency of secondary embryogenesis was obtained in the cotyledons $(90 \%)$ and hypocotyls $(83.33 \%)$ on $\mathrm{MS}$ medium with $1.0 \mathrm{mg} / \mathrm{L} 2,4-\mathrm{D}$. The average number of secondary embryos per explant was 25.74 in cotyledon and 24.92 in hypocotyl. When the cotyledon and hypocotyl segments from somatic embryos at different developmental stages were cultured on MS medium with 1.0 $\mathrm{mg} / \mathrm{L} \mathrm{2,4-D}$, the highest frequency of secondary embryogenesis was obtained from late cotyledonary secondary embryos. Somatic embryos were transferred to MS basal medium and then they germinated within 2 to 4 weeks of culture. Germinated somatic embryos grew normally into plantlets on WPM medium, producing new shoots. The converted plantlets were acclimatized on artificial soil mixture. These results indicate that the repetitive secondary somatic embryogenesis in $T$. amurensis can offer the possibility to use in vitro culture system for the micropropagation.
\end{abstract}

\section{Introduction}

Tilia amurensis, one of major local trees in the central region of Korea, is used as plant of producing the plentiful honey of good quality, and can be found in streets or parks

* Corresponding author: e-mail: ktd747@hanmail.net

Received Nov. 3, 2006; Accepted Nov. 18, 2006 owing to the beautiful crown shape and the sweet smell of flowers. Its wood and bark have been used for furniture, sculpture, pencils, straw ropes, and mats.

The propagation of Tilia species through seeds is known to be difficult due to impermeable seed coat and long period of seed dormancy. The cutting propagation also is not efficient because of poor root systems from cuttings (Lee and Suh 1989, Morsink and Smith 1974, 1975).

Plant regeneration through in vitro plant tissue culture is an attractive protocol for propagation of plants, especially in plants having difficulty by conventional propagation method. To overcome this difficulty of propagation, micropropagation of Tilia cordata through auxiliary bud culture was reported (Youn and Ohba 1990, Youn et al. 1988). Somatic embryogenesis has been known to be more efficient than other culture methods in the massive plant production. Plant regeneration via somatic embryogenesis ,from zygotic embryos of Tilia cordata have been studied (Chalupa 1990, Kärkönen 2000). In Tilia amurensis, somatic embryogenesis was induced from primary leaf of germinating seedling but germination and plant regeneration from cotyledonary somatic embryos were failed (Kim et al. 1990). Kim et al. (1988) reported that somatic embryogenesis from hypocotyl derived callus of Tilia amurensis. Repetitive secondary somatic embryogenesis offers the possibility of large scale multiplication of plant material. Furthermore, embryogenic potential can be maintained for prolonged periods by repeated cycles of secondary embryogenesis (Raemakers et al. 1995). In Tilia amurensis, there has been no report on the micoropropagation via repetitive secondary somatic embryogenesis.

The objective of the present work was to establish continuous in vitro propagation system by investigating efficient secondary somatic embryogenesis from explants of somatic embryo derived from mature seeds of $T$. amurensis. 


\section{Materials and Methods}

\section{Plant Materials}

Mature seeds of Tilia amurensis Rupr were collected in Forest Seed Research Center, KFRI during September. The seeds were sterilized in $70 \%$ ethanol for $1 \mathrm{~min}$, followed by disinfecting in $2 \%$ sodium hypochlorite solution for $8 \mathrm{~min}$, and rinsed 5 times in sterile distilled water.

\section{Primary Somatic Embryogenesis}

After mature zygotic embryos (cotyledonary stage) were dissected out from the seeds with a surgical blade, they were cut into 3 different parts (cotyledon, hypocotyl or radicle) and placed on MS medium (Murashige and Skoog 1962) containing various concentrations of 2,4-D $(0.5,1.0$ or $2.0 \mathrm{mg} / \mathrm{L})$. The media were solidified with $0.3 \%$ gelrite and adjusted to $5.8 \mathrm{pH}$ before autoclaving at $121^{\circ} \mathrm{C}$ for 15 min. The culture room was maintained at $25 \pm 2^{\circ} \mathrm{C}$ in darkness. The frequency of somatic embryogenesis was evaluated by counting explants producing somatic embryos from the total number of cultured explants after 6 weeks of culture. Five explants were cultured in each petri dish. Each experiment was performed 4 times.

\section{Secondary Somatic Embryogenesis}

To find proper types and concentrations of growth regulators as well as optimal types of culture explants for secondary somatic embryogenesis, 3 different parts (cotyledon, hypocotyl or radicle) of cotyledonary somatic embryos were transferred to MS medium supplemented with auxin (2,4-D, NAA, IBA or IAA; $0.5,1.0$ or $2.0 \mathrm{mg} / \mathrm{L}$ ) or cytokinin (BA or kinetin; $0.5,1.0$ or $2.0 \mathrm{mg} / \mathrm{L}$ ) alone, and containing both auxin (2,4-D; $1.0 \mathrm{mg} / \mathrm{L}$ ) and cytokinin (BA or kinetin; 0.1, 0.25 or $0.5 \mathrm{mg} / \mathrm{L}$ ).

The effect of sucrose concentrations on secondary embryogenesis was observed by inoculating cotyledon or hypocotyl segments of cotyledonary somatic embryos on MS medium containing $1.0 \mathrm{mg} / \mathrm{L} \mathrm{2,4-D}$ with different sucrose levels $(0,0.5,1,3,6$ or $9 \%)$

To study the effect of somatic embryo developmental stages on secondary embryogenesis, cotyledon and hypocotyl segments from somatic embryos at 4 different stages [midcotyledonary $(3.7 \mathrm{~mm})$, later-cotyledonary $(5.8 \mathrm{~mm})$, earlygerminated $(8.8 \mathrm{~mm})$ or 3 -week-old-germinated $(27 \mathrm{~mm})$ ] were inoculated on MS medium with $1.0 \mathrm{mg} / \mathrm{L} \mathrm{2,4-D.}$

The frequency of secondary embryogenesis was evaluated by counting explant producing secondary embryos after 6 weeks of culture. Five explants were cultured in each petri dish. Each experiment was performed 6 times.

\section{Somatic Embryo Germination and Plant Regeneration}

When early somatic embryos (globular to torpedo stages) were isolated from mother tissue and inoculated on MS medium lacking growth regulators, all of them developed into cotyledonary embryos after 3 to 4 weeks. To germinate somatic embryos, cotyledonary embryos were transferred to MS basal medium. Germinated somatic embryos were transferred to WPM (Lloyd and McCown 1980), MS, 1/2MS, DKW (Driver and Kuniyuki 1984) or GD (Gresshoff and Doy 1972) medium in order to convert somatic embryos into plantlets. The culture room was maintained at $25 \pm 2{ }^{\circ} \mathrm{C}$ with a 16 hour photoperiod under $30 \mu \mathrm{mol} \mathrm{m} \mathrm{m}^{-2} \mathrm{cool}$ white fluorescent light. The frequency of plantlet conversion from somatic embryos was evaluated by counting plantlets with well-developed shoots and roots after 2 months of culture. Twenty somatic embryos were cultured in each petri dish. Each experiment was performed 10 times.

The plantlets with well-developed shoots and roots were acclimated in artificial soil [pelrite, vermiculrite, peatmoss $1: 1: 1(v / v)]$ for 1 month of culture. They were transplanted in plastic pots containing pelrite, vermiculrite and peatmoss $(1: 1: 1 \mathrm{v} / \mathrm{v})$ and then transferred to a greenhouse. After 2 months, survival of plants was assessed. Twenty plants were planted in artificial soil and each experiment was performed 5 times.

\section{Results and Discussion}

\section{Secondary Somatic Embryogenesis}

Primary and secondary somatic embryos (globular stage) were formed directly' on the surface of cotyledon and hypocotyl explants from mature zygotic and somatic embryos after about 4 weeks of culture but radicle explants did not produce somatic embryos (Figure 1A, 1B and 1C). Secondary somatic embryos were morphologically identical to primary somatic embryos formed from zygotic embryo explants. However, the frequency of somatic embryogenesis showed significant difference between primary and secondary embryogenesis according to explants types (zygotic embryos or somatic embryos) as shown in Table 1 and 2 .

When explants were cultured on MS medium with 1.0 $\mathrm{mg} / \mathrm{L} 2,4-\mathrm{D}$, the frequency of primary embryogenesis from zygotic embryos was $15 \%$ (cotyledons) or $25 \%$ (hypocotyls) Whereas the frequency of secondary embryogenesis from somatic embryos was $90 \%$ (cotyledons) or $83 \%$ (hypocotyls). Numbers of somatic embryos per explant from zygotic embryos were 7.67 in cotyledons and 9.80 in hypocotyls. Numbers of secondary somatic embryos per explant of primary explants were 25.74 in cotyledons and 24.92 in hypocotyls. Consequently, these results indicate that efficiency of secondary embryogenesis is higher than primary 


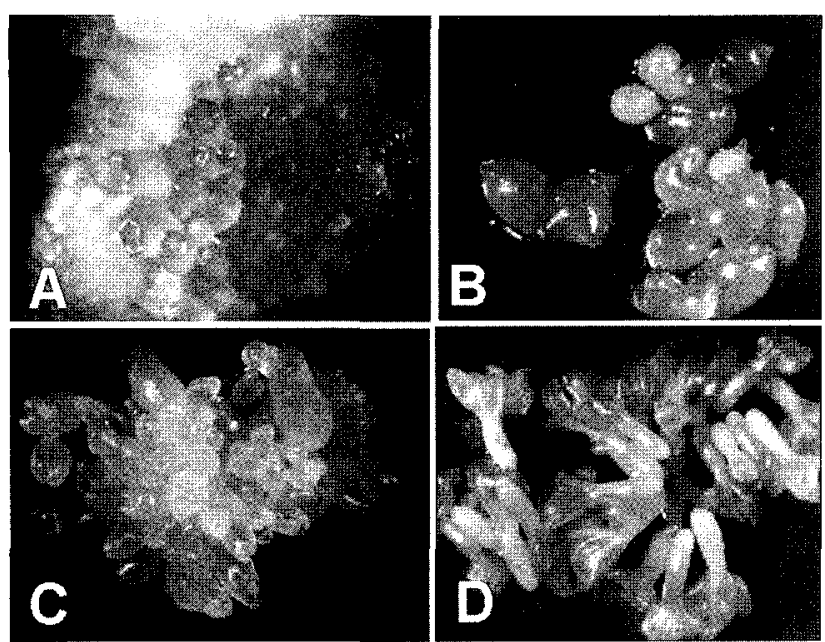

Figure 1. Direct secondary somatic embryogenesis from somatic embryos in $T$. amurensis. A. Secondary somatic embryos formed directly on the surface of somatic embryos on MS medium with $1.0 \mathrm{mg} / \mathrm{L}$ 2,4-D after 6 weeks of culture. B. Heart-shaped embryos formed from hypocotyl explants of somatic embryos after detaching from hypocotyl and cotyledon explants. C. Torpedo embryos formed from cotyledon explants of somatic embryo. D. Cotyledonary somatic embryos developed on MS medium. embryogenesis and also in agreement with the observations of Catarina et al. (2004) on repetitive somatic embryogenesis of Ocotea catharinensis.

The highest frequency of secondary embryogenesis was obtained in the cotyledon $(90 \%)$ and hypocotyl $(83.33 \%)$ segments cultured on MS medium with $1.0 \mathrm{mg} / \mathrm{L} \mathrm{2,4-D.} \mathrm{The}$ average number of secondary embryos formed per explant also was the highest in cotyledons (25.74) compared to hypocotyl (24.92) and radicle (0) (Table 2). No significant differences in the formation of secondary somatic embryos were observed between cotyledon and hypocotyl segments

The explants cultured on MS basal medium lacking growth regulators produced only a few secondary embryos. The auxins including NAA, IBA and IAA induced the formation of secondary somatic embryos but the production of secondary embryogenesis was less effective than 2,4-D used.

The presence of cytokinin (BA or kinetin) in the culture medium was not effective (Table 3 ). The MS medium supplemented with BA or kinetin alone did not induce secondary somatic embryos. Explants cultured on MS medium containing both 2,4-D and BA also did not produce secon-

Table 1. The frequency of somatic embryogenesis from 3 different explants of mature zygotic embryos on MS medium with 2,4-D at various concentrations.

\begin{tabular}{|c|c|c|c|c|c|c|c|}
\hline \multirow{2}{*}{\multicolumn{2}{|c|}{$\begin{array}{l}\text { Plant growth } \\
\text { regulator } \\
\text { (mg/L) }\end{array}$}} & \multicolumn{3}{|c|}{$\begin{array}{l}\text { Somatic embryo induction } \\
(\% \pm \text { SE) }\end{array}$} & \multicolumn{3}{|c|}{$\begin{array}{l}\text { No. of somatic embryo } \\
\text { per exlant (Mean } \pm S E \text { ) }\end{array}$} \\
\hline & & Cotyledon & Hypocotyl & Radicle & Cotyledon & Hypocotyl & Radicle \\
\hline & & - & - & - & - & - & - \\
\hline \multirow{3}{*}{$2,4-D$} & 0.5 & $15.00 \pm 0.25$ & $20.00 \pm 0.41$ & - & $6.00 \pm 1.32$ & $9.25 \pm 1.75$ & $=$ \\
\hline & 1.0 & $15.00 \pm 0.48$ & $25.00 \pm 0.25$ & - & $7.67 \pm 1.81$ & $9.80 \pm 1.83$ & - \\
\hline & 2.0 & $10.00 \pm 0.50$ & $10.00 \pm 0.29$ & - & $4.50 \pm 0.50$ & $8.00 \pm 4.00$ & - \\
\hline
\end{tabular}

Table 2. The frequency of secondary somatic embryogenesis from 3 different explants of primary somatic embryos on MS medium with $2,4-D, N A A, I B A$ or IAA at various concentrations.

\begin{tabular}{|c|c|c|c|c|c|c|c|}
\hline \multirow{2}{*}{\multicolumn{2}{|c|}{$\begin{array}{l}\text { Plant growth } \\
\text { regulators } \\
(\mathrm{mg} / \mathrm{L})\end{array}$}} & \multicolumn{3}{|c|}{$\begin{array}{c}\text { Somatic embryo induction } \\
(\% \pm S E)\end{array}$} & \multicolumn{3}{|c|}{$\begin{array}{l}\text { No. of somatic embryo } \\
\text { per explant (Mean } \pm \text { SE) }\end{array}$} \\
\hline & & Cotyledon & Hypocotyl & Radicle & Cotyledon & Hypocotyl & Radicle \\
\hline & & $16.67 \mathrm{hg}^{*} \pm 0.40$ & $23.33 \mathrm{~cd} \pm 0.48$ & - & $3.20 \pm 0.21$ & $6.29 \pm 0.54$ & - \\
\hline \multirow{3}{*}{$2,4-D$} & 0.5 & $86.67 a b \pm 0.21$ & $81.35 a \pm 0.40$ & - & $22.65 \pm 2.18$ & $17.88 \pm 1.68$ & - \\
\hline & 1.0 & $90.00 a \pm 0.22$ & $83.33 a \pm 0.48$ & - & $25.74 \pm 3.58$ & $24.92 \pm 3.55$ & - \\
\hline & 2.0 & $83.33 a b \pm 0.17$ & $79.37 a \pm 0.31$ & - & $23.20 \pm 2.48$ & $14.68 \pm 1.54$ & - \\
\hline \multirow{3}{*}{ NAA } & 0.5 & $20.00 \mathrm{fgh} \pm 0.37$ & $40.00 b c \pm 0.45$ & - & $6.67 \pm 0.84$ & $8.33 \pm 1.28$ & - \\
\hline & 1.0 & $21.67 \mathrm{fgh} \pm 0.31$ & $36.67 \mathrm{bcd} \pm 0.48$ & - & $7.29 \pm 1.11$ & $9.09 \pm 1.32$ & - \\
\hline & 2.0 & $23.33 \mathrm{fgh} \pm 0.40$ & $43.33 b c \pm 0.17$ & - & $7.86 \pm 1.49$ & $10.00 \pm 1.28$ & - \\
\hline \multirow{3}{*}{ IBA } & 0.5 & $66.67 a b c \pm 0.33$ & $73.33 a \pm 0.21$ & - & $20.00 \pm 3.01$ & $21.27 \pm 2.65$ & - \\
\hline & 1.0 & $76.67 a b \pm 0.31$ & $80.00 a \pm 0.26$ & - & $21.74 \pm 2.47$ & $22.71 \pm 3.17$ & - \\
\hline & 2.0 & $63.33 \mathrm{bcd} \pm 0.31$ & $73.33 a \pm 0.21$ & - & $18.95 \pm 2.18$ & $21.36 \pm 2.01$ & - \\
\hline \multirow{3}{*}{ IAA } & 0.5 & 36.67 efg \pm 0.48 & $60.00 a b \pm 0.26$ & - & $10.27 \pm 1.65$ & $13.78 \pm 1.73$ & - \\
\hline & 1.0 & $43.33 c d e f \pm 0.31$ & $47.72 b c \pm 0.48$ & - & $11.23 \pm 1.49$ & $15.54 \pm 1.59$ & - \\
\hline & 2.0 & 40.00 defg \pm 0.37 & $43.33 b c \pm 0.40$ & - & $11.25 \pm 1.39$ & $12.31 \pm 1.84$ & - \\
\hline
\end{tabular}

"Mean separation within columns by Duncan' multiple range test at $1 \%$ level 
Table 3. The frequency of secondary somatic embryogenesis from 3 different explants of primary somatic embryos on MS medium containing both 2,4-D and kinetin or BA.

\begin{tabular}{|c|c|c|c|c|c|c|c|c|}
\hline \multicolumn{3}{|c|}{$\begin{array}{l}\text { Plant growth } \\
\text { regulators }(\mathrm{mg} / \mathrm{L})\end{array}$} & \multicolumn{3}{|c|}{$\begin{array}{l}\text { Somatic embryo induction } \\
\qquad(\% \pm \text { SE })\end{array}$} & \multicolumn{3}{|c|}{$\begin{array}{l}\text { No. of somatic embryo } \\
\text { per explant (Mean } \pm S E \text { ) }\end{array}$} \\
\hline 2,4-D & kinetin & $\mathrm{BA}$ & Cotyledon & Hypocotyl & Radicle & Cotyledon & Hypocotyl & Radicle \\
\hline \multirow{3}{*}{1.00} & 0.10 & 0.00 & $50.00 \mathrm{cde}^{\star} \pm 0.24$ & $33.33 \mathrm{~cd} \pm 0.20$ & - & $11.2 \mathrm{C} \pm 1.35$ & $20.20 \pm 4.06$ & - \\
\hline & 0.25 & 0.00 & $26.67 \mathrm{fgh} \pm 0.20$ & $30.00 \mathrm{~cd} \pm 0.24$ & - & $17.13 \pm 3.00$ & $14.33 \pm 1.80$ & - \\
\hline & 0.50 & 0.00 & $6.67 \mathrm{~h} \pm 0.24$ & $13.33 \mathrm{~d} \pm 0.24$ & - & $9.00: t 1.00$ & $9.25 \pm 2.17$ & - \\
\hline \multirow{3}{*}{1.00} & 0.00 & 0.10 & - & - & - & - & - & - \\
\hline & 0.00 & 0.25 & - & - & - & - & - & - \\
\hline & 0.00 & 0.50 & - & . & - & . & - & - \\
\hline
\end{tabular}

'Mean separation within columns by Duncan' multiple range test at $1 \%$ level.
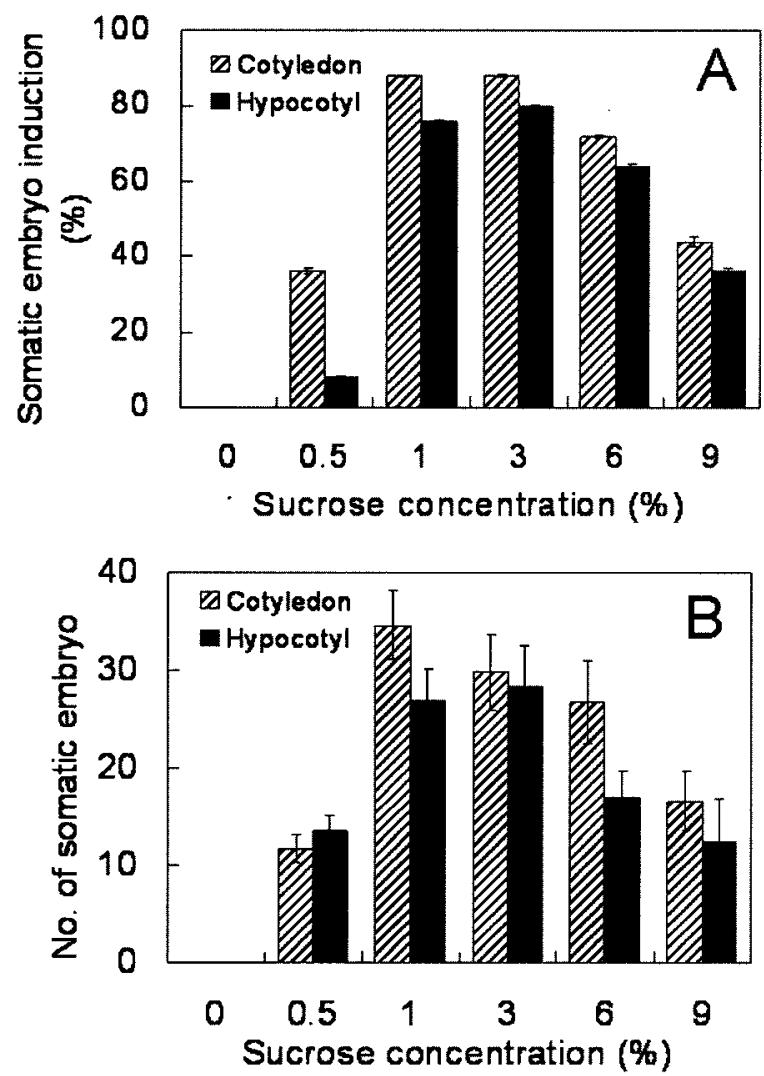

Figure 2. Effect of various sucrose concentrations on the frequency (A) and number (B) of secondary somatic embryos from cotyledons and hypocotyls of somatic embryos on MS medium with $1.0 \mathrm{mg} / \mathrm{L} \mathrm{2,4-D}$ after 6 weeks of culture.

dary embryos. MS medium containing only both 2,4-D and kinetin produced secondary somatic embryos from cultured explants. When kinetin was added to MS medium with 2,4-D, somatic embryo production decreased with increasing concentrations of the kinetin (Table 3). Therefore kinetin was not effective on secondary somatic embryogenesis although secondary somatic embryos were produced on MS medium with combinations of 2,4-D and kinetin. Consequently, $2,4-D$ at the concentrations of $1.0 \mathrm{mg} / \mathrm{L}$ was the most effective for inducing secondary embryos from primary somatic embryos of $T$. amurensis.
Influence of auxins and/or cytokinins on secondary somatic embryogenesis tends to show different responses depending on species. As a result of the present study on $T$. amurensis, it was found that 2,4-D was highly effective to induce secondary somatic embryos from primary somatic embryos, whereas NAA did not, and that the presence of $B A$ or kinetin in the medium was not effective. However, in Manihot esculenta (Sofiari et al. 1997) not only 2,4-D but also NAA medium induced secondary somatic embryogenesis and the number of somatic embryos formed was more higher in NAA than in 2,4-D. In Morus alba (Agarwal et al. 2004), secondary scimatic embryos were induced in medium with a combination of 2,4-D and BA.S

The optimal concentrations of sucrose on somatic embryogenesis vary eccording to plant materials. In Morus alba (Agarwal et al. 2004), sucrose at $6 \%$ was most effective and showed the highest percentage of secondary somatic embryogenesis. In Euonymus euonymus (Biahoua and Bonneau 1999) the highest frequency of somatic embryogenesis from zygotic embryo explants was obtained with a $350 \mathrm{mM}$ sucrose. In $T$. amurensis, concentration of sucrose in culture medium had a significant effect on secondary somatic embryogenesis (Figure 2). The presence of sucrose led to form secondary embryos, whereas the absence of sucrose did not. In cotyledons, the highest frequency of seconclary embryogenesis $(88 \%)$ was obtained in culture medium containing $1 \%$ or $3 \%$ sucrose. The average number of secondary embryos formed per explant (34.55) was the highest at $1 \%$. In hypocotyls, both the frequency of secondary embryogenesis (80\%) and the average number of secondary embryos formed per explant (28.32) were the highest at $3 \%$. At the lowest $(0.5 \%)$ and highest $(9 \%)$ concentrations, sucrose reduced secondary embryogenesis. Consequently the proper concentration of sucrose for secondary embryogenesis from primary somatic embryos in $T$. amurensis was $3 \%$.

Cotyledon and hypocotyl segments from 4 different developmental stages of primary somatic embryos (midcotyledonary, later-cotyledonary, early-germinated or 3-weekold-germinated) were cultured on MS medium with 1.0 $\mathrm{mg} / \mathrm{L}$ 2,4-D. As shown in Table 4, the highest frequency of 
Table 4. Percentage of secondary somatic embryogenesis from cotyledon and hypocotyl explants of somatic embryos at the different developmental stages.

\begin{tabular}{lcccccc}
\hline $\begin{array}{c}\text { Developmental stages } \\
\text { (Explants) }\end{array}$ & $\begin{array}{c}\text { Size } \\
(\mathrm{mm})\end{array}$ & \multicolumn{2}{c}{ Somatic embryo induction (\% $\pm \mathrm{SE})$} & \multicolumn{2}{c}{$\begin{array}{c}\text { No. of somatic embryo } \\
\text { per explants (mean } \pm S E)\end{array}$} \\
\cline { 3 - 7 } & 3.7 & Cotyledon & Hypocotyl & Cotyledon & Hypocotyl \\
\hline Mid-cotyledonary & $80.00 \mathrm{a}^{*} \pm 0.32$ & $56 \mathrm{~b} \pm 0.26$ & $22.25 \pm 4.36$ & $32.50 \pm 5.61$ \\
\hline Late-cotyledonary & 5.8 & $88.00 \mathrm{a} \pm 0.32$ & $84 \mathrm{a} \pm 0.48$ & $38.86 \pm 4.04$ & $37.71 \pm 5.13$ \\
\hline Early-germinated & 8.8 & $20.00 \mathrm{~b} \pm 0.41$ & $48 \mathrm{~b} \pm 0.52$ & $9.40 \pm 2.09$ & $25.42 \pm 3.34$ \\
\hline 3 week-old-germinated & 27.0 & - & - & - & - \\
\hline
\end{tabular}

*Mean separation within columns by Duncan' multiple range test at $1 \%$ level.
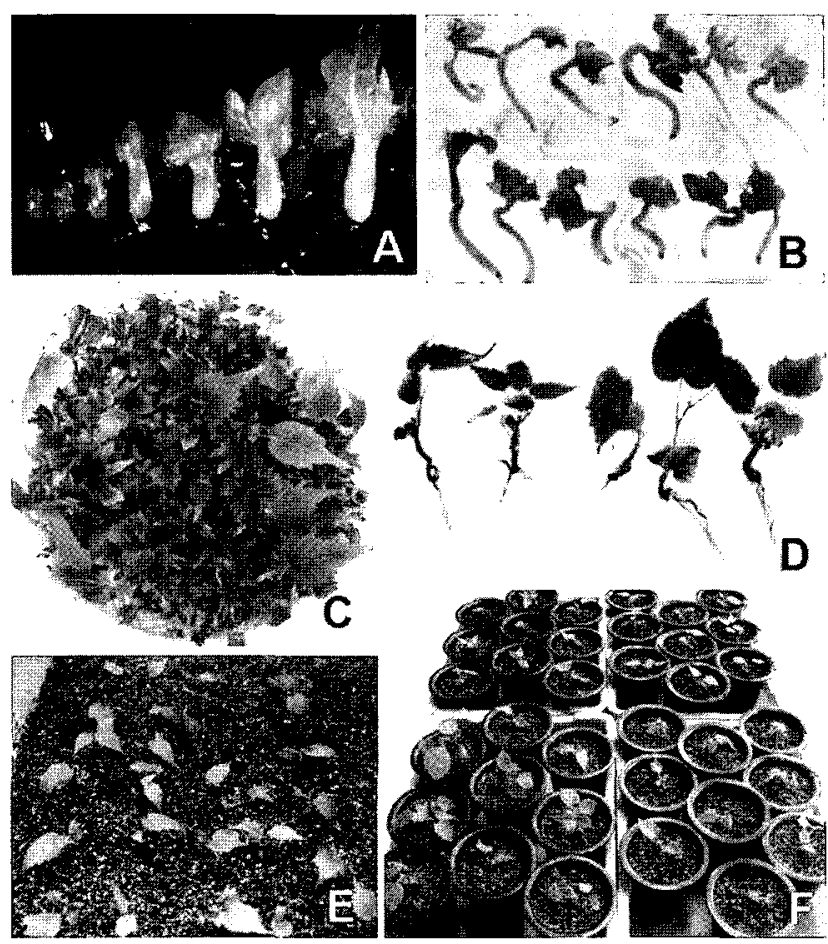

Figure 3. Plant regeneration via direct secondary somatic embryogenesis in $T$. amurensis. A. Various stage of secondary somatic embryos formed on the surface of hypocotyl explants of somatic embryos on MS medium with $1.0 \mathrm{mg} / \mathrm{L} \mathrm{2,4-D}$ after 6 weeks of culture. B. Germinating somatic embryos after 2 to 3 weeks on MS medium. C. Plantlets grown in WPM medium after 2 months of culture. D. Isolated plantlets from C. E. Plantlets acclimatized in artificial soil after 4 weeks. F. Plants after transfer to greenhouse.

explants producing secondary embryos was $88 \%$ and $84 \%$ from cotyledon and hypocotyl segments of later-cotyledonary somatic embryos. Cotyledon and hypocotyl explants from later-cotyledonary somatic embryos also produced the highest number of secondary somatic embryos ( 38.86 and 37.71 , respectively). In the explants of early-germinated somatic embryos, secondary embryogenesis was significantly reduced. In the explants from 3 week-old-germinated embryos, secondary somatic embryos did not formed. Consequently, these results indicate that it is necessary to use later-cotyledonary somatic embryos as explants for the effective secondary embryogenesis. These results are in agreement with the observations of Catarina et al. (2004)

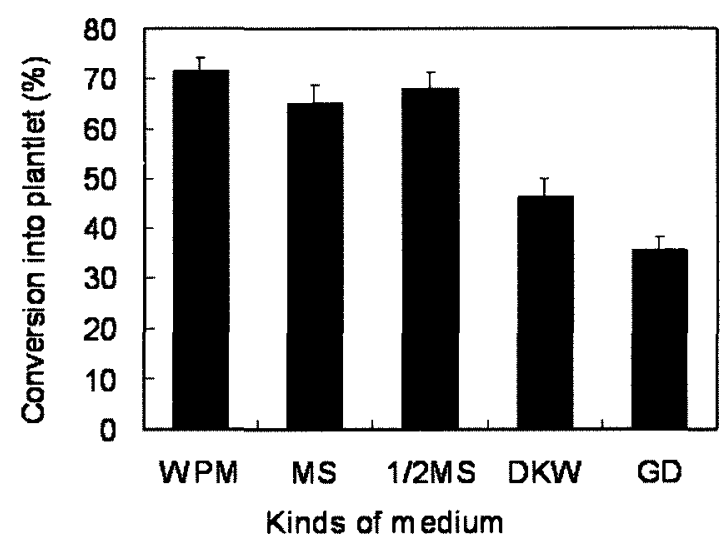

Figure 4. Frequency of plantlet conversion from secondary somatic embryos of $T$. amurensis on various media after 2 months of culture. Vertical bars represent the mean vaules $\pm S D$.

on repetitive somatic embryogenesis of Ocotea catharinensis.

The maturation of somatic embryos was easily achieved on MS medium without any growth regulators or additives. When early somatic embryos were removed from maternal explants and then transferred to MS basal medium, they were developed into normal cotyledonary embryos within 2 to 4 weeks of culture (Figure 1B-D). Each somatic embryo was easily separated from maternal explants since they were loosely attached to the surface of explants.

\section{Somatic Embryo Germination and Plant Conversion}

When cotyledonary somatic embryos were transferred to MS medium lacking growth regulators, more than $90 \%$ of them germinated after 2 to 3 weeks of culture (Figure $3 A-B)$. The first signals of somatic embryo germination was the red color accumulation on the surfaces of radicles after one week of culture (Figure 3B).

The highest frequency of plantlet conversion from somatic embryos (71.5\%) was obtained in WPM medium (Figure 4). When germinated somatic embryos were subcultured individually on WPM medium, their hypocotyls and radicles began to elongate further after one week of culture and then they converted into plantlets with well-developed shoots and roots after 2 months (Figure 3 C-D). 
When plantlets derived from somatic embryos were acclimated in artificial soils (Figure $3 E$ ) and then transferred to greenhouse, about $74 \%$ of the plants survived after 2 months of culture as shown in Figure 3F. Conclusively, high frequency repetitive secondary somatic embryogenesis can afford to propagate the T. amurensis effectively. This protocol can be applied to produce transgenic plants of $T$. amurensis.

\section{Acknowledgements}

This work was supported by grant from the Korea Forest Service, Republic of Korea.

\section{References}

Agarwal S, Kanwar K, Sharma DR (2004) Factors affecting secondary somatic embryogenesis and embryo maturation in Morus alba L. Scientia Horticulturae 102: $359-368$

Biahoua A, Bonneau L (1999) Control of in vitro somatic embryogenesis of spindle tree (Euonymus europaeus L.) by the sugar type and the osmotic potential of the culture medium. Plant Cell Rep 19: 185-190

Catarina CS, dos Santos Olmedo A, de Andrade Meyer G, Macedo J, de Amorim W, Viana AM (2004) Repetitive somatic embryogenesis of Ocotea catharinensis Mez. (Lauraceae): effect of somatic embryo developmental stage and dehydration. Plant Cell Tiss Org Cult 78: 55-62

Chalupa $V(1990)$ Plant regeneration by somatic embryogenesis from cultured immature embryos of oak (Quercus robur L.) and linden (Tilia cordata Mill.). Plant Cell Rep 9: 398-401

Driver JA, Kuniyuki AH (1984) In vitro propagation of paradox walnut rootstock. HortSci 19: 507-509

Gresshoff PM, Doy CH (1972) Development and differentiation of haploid Lycopersicon esculentum (tomato). Planta 107: 161-170

Kim JH, Moon HK, Park JI, Lee BC (1988) Somatic embryogenesis and plant regeneration in callus from hypocotyl segments of Tilia amurensis. In: Genetic Manipulation of Woody Plants. JW! Hanover and DE keathley (eds) Plenum Press, New York, pp 473-474

Kim MJ, Hyun JO, Kim SJ, Kim IS (1990) In vitro induction of somatic embryos trom primary leaf tissues of Tilia amurensis seedling. Kor $\mathrm{J}$ f:piculture 5: 35-42

Kärkönen A (2000) Anatomical study of zygotic and somatic embryos of Tilia cordata. Plant Cell, Tiss Org Cult 61: 205-214

Lee D K, Suh MH (1989) Propagation of Tilia species by cutting. Kor J Apiculture 4: 56-60

Lloyd E, McCown B (1980) Commercially feasible micropropagation of mountain laurel, Kalmia latifolia, by use of shoot tip cuiture. Proc Intl Plant Prop Soc 30:421-427

Morsink WAG, Smith VG (1974) Root and shoot development on cuttings of basswood (Tilia americana) as affected by auxin treatments and size cuttings. Can $J$ For Res 4: 246-249

Morsink WAG, Smith VG (1975) The effect of some monohydroxybenzoic and dihydroxybenzoic acids as auxin synergists on rooting softwood cuttings of basswood (Tilia americana L.) under mist. Can J For Res 5: 500-502

Murashige T, Skoog F (1962) A revised medium for rapid growth and bioassays with tobacco tissue. Physiol Plant 15: $473-497$

Raemakers CJJM, Jacobsen E, Visser RGF (1995) Secondary somatic embryogenesis and applications in plant breeding. Euphytica 81: 93-107

Sofiari E, Raemakers CJJM, Kanju E, van Lammeren AM, Jacobsen E, Visser RGF (1997) Comparison of NAA and 2,4-D induced somatic embryogenesis in Cassava. Plant Cell Tiss Org Cult 50: $45-56$

Youn $Y$, Ohba $K(1990)$ In vitro plantlet regeneration from axillary buds of Tilia amurensis mature trees and clonal variation in tissue culturability. $J$ Kor For Soc 79: 109-114

Youn Y, Ishii K, Saito A, Ohba K (1988) In vitro plantlet regeneration from axillary buds of mature trees of Tilia cordata. J Jpn For Soc 70: 315-317 